
\title{
25 Research Square \\ Digital anatomical study of screw placement for quadrilateral plate through the middle window of ilioinguinal approach
}

\section{Bei Zhao}

Liaocheng People's Hospital

Weidong Mu ( $\sim$ Dr_muweidong@163.com )

hospital

\section{Research article}

Keywords: Acetabular fracture, Quadrilateral plate, Screw placement, Digital measurement

Posted Date: October 16th, 2019

DOI: https://doi.org/10.21203/rs.2.16062/v1

License: (c) (1) This work is licensed under a Creative Commons Attribution 4.0 International License.

Read Full License 


\section{Abstract}

Background Screw placement directly for quadrilateral plate fractures of the acetabulum is very difficult. This study was performed to simulate the surgical procedure and try to obtain effective and safe screw angles through the middle window of ilioinguinal approach in Chinese patients.

Methods We randomly collected the pelvic computed tomography (CT) scans of 50 adults. DICOMformatted CT-scan images were imported into Mimics software. The three-dimensional reconstruction (3D) digital model of the semi-pelvic was established. In the coronal and sagittal planes, a $3.5 \mathrm{~mm}$ cylinder was used to simulate the pathway of the screw from the designated insertion point. The angles of insertion and intersex differences were explored by statistical analyses.

Results The screws could be inserted via four angles: medial inclination, lateral inclination, anterior inclination and posterior inclination. The mean minimum medial inclination angle (MIMIA) of insertion point $A$ was $4.96^{\circ} \pm 1.11^{\circ}$ in males and $8.66^{\circ} \pm 3.40^{\circ}$ in females, and the intersex difference was significant. The mean minimum medial inclination angle (MIMIA) of insertion point $C$ was $-5.31^{\circ} \pm 3.69^{\circ}$ in males and $1.75^{\circ} \pm 8.95^{\circ}$ in females, and the intersex difference was significant. There were no differences in all the angles between males and females in insertion point $B$.

Conclusions Preoperative measurement and calculation by digital tools before the screw placement for quadrilateral plate fractures of the acetabulum are feasible. Double cortical screws could be placed safely through the middle window of ilioinguinal approach to increase the stability of acetabulum.

\section{Background}

The ilioinguinal approach is a standard anatomical approach that gives an excellent visual and exposure of the quadrilateral plate through the middle window[1]. Unfortunately, screw placement for acetabular fracture is difficult for its complicated geometry, especially when operated at dangerous zone of acetabulum for the treatment of displaced quadrilateral plate fractures. The wrong direction of screws may lead to the high risk of penetrating into the articular surface and traumatic hip arthritis[2].

Many experts have studied this region and have analyzed screw implants in cadavers[3-5]. It is very difficult to place a double cortical screw directly in the danger zone to fix the quadrilateral plate[6,7]. Several techniques have been reported to prevent the complication of screw placement at the dangerous region of acetabulum. However, these methods might increase operation time and cause iatrogenic trauma[8-10]. Therefore, how to find the accurate points of insertion, lengths and the angles of screws are of high value before the surgery[11].

To date, a large amount of computer software related to orthopaedics have been reported to measure the safety of screw implantation[12-14]. Materialise's Interactive Medical Image Control System (Mimics), which often used for three-dimensional reconstruction, simulating operations with the use of internal fixation and analyzing data, might be a more efficient method for implants[15-17]. Thus, we simulated 
the surgical procedure by using Mimics software and attempted to obtain safe and effective screw angles for the quadrilateral plate of the acetabulum in Chinese patients.

\section{Materials And Methods}

We retrospectively collected the pelvic computed tomography (CT) scans (digital imaging and communication in medicine format) of 100 adults who had undergone continuous slice CT scanning at the imaging research center of our hospital between September 2017 and February 2019. Patients were excluded if they had pelvic or acetabular fractures, tumors, severe deformities, or severe hip inflammation and degeneration. This study was approved by the Institutional Review Board of our hospital, and patients' informed consent was obtained. A total of 25 male and 25 female virtual pelvic models were created. The mean age of the patients on whom the models were based was 47.5 years (range 18-79 years).

DICOM-formatted CT-scan images of each patient were imported into Mimics software (20.0; Materialise, Leuven, Belgium). We removed the soft tissue by image segmentation, removing the femoral head through region growth, and we removed the sacroiliac joint through multiple slice editing. The threedimensional reconstruction (3D) digital model of the semi-pelvic was established.

Then, we performed plate placement on the superior border of the arcuate line in the semi-pelvic 3D reconstruction (Fig 1). The distance between the plate hole and the arcuate line was $5 \mathrm{~mm}$ (the width of the commonly used $3.5 \mathrm{~mm}$ reconstruction plate was $10 \mathrm{~mm}$, so the insertion pionts for the screws were $5 \mathrm{~mm}$ from the pelvic boundary). Insertion point B (plate hole B) corresponded to the-thinnest medial wall of the acetabulum. Insertion point $\mathrm{A}$ and $\mathrm{C}$ were the two holes close to plate hole B, respectively (Fig 1 ).

The $3.5 \mathrm{~mm}$ cylinders were employed to simulate the pathways of the screws from the insertion points $A$, $B$ and $C$. The screws were in three directions: medial inclination (perpendicular to the plane of the quadrilateral plate), anterior inclination and posterior inclination (parallel to the plane of the quadrilateral plate). In this procedure, screws were inserted tangential to the margins of the acetabular cortex, penetrating into the bilateral cortices. When performed medial inclination, screws with lengths of $14 \mathrm{~mm}$ tilted inward into the quadrilateral cortex were also simulated (Figs 2-4).

The angle between the reference line (black line: parallel to the quadrilateral plate and perpendicular to the arcuate line) and the screw tangential to the medial margin of the acetabular cortex was the minimum medial inclination angle (MIMIA). The angle between the reference line and the screw with a length of $14 \mathrm{~mm}$ was the maximum medial inclination angle (MAMIA). The angles between the reference line and the screws tangential to the anterior and posterior margins of the acetabular cortex were the minimum anterior inclination angle (MIAIA) and minimum posterior inclination angle (MIPIA), respectively. The MIMIA, MAMIA, MIAIA and MIPIA were measured (Figs 2-4).

The collected data were analyzed by SPSS 19.0 statistical software. The experimental data are represented as the mean \pm SD. T tests were used to compare the data. Statistical significance was 
accepted at $\mathrm{p}<0.05$.

\section{Results}

The study subjects included 25 males and 25 females aged between 18 and 79 years old, with a mean age of $53.03 \pm 18.99$ years. We observed that the screws could be inserted via four angles: the minimum medial inclination, the maximum medial inclination, anterior inclination and posterior inclination.

As viewed from insertion point $A$, the mean MIMIA was $4.96^{\circ} \pm 1.11^{\circ}$ in males and $8.66^{\circ} \pm 3.40^{\circ}$ in females, and the intersex difference was significant $(P<0.05$, Table 1). The mean MAMIA was not statistically significant in different sexes ( $P>0.05$, Table 1). In males, the mean MIAIA and MIPIA were $-1.49^{\circ} \pm 6.29^{\circ}$ and $45.75^{\circ} \pm 6.13^{\circ}$, respectively, from the view of insertion point $A$; in females, the values were $-1.81^{\circ}$ $\pm 7.58^{\circ}$ and $48.45^{\circ} \pm 14.69^{\circ}$, respectively (the negative value of the MIAIA indicated that the screw was placed in posterior inclination rather than in anterior inclination). However, the results were not statistically significant between males and females $(P>0.05$, Table 1$)$.

As viewed from insertion point $B$, the insertion angle of the screw is recommended to be smaller in males than that in females, but no significant differences were found in the inward tilt of the screws. In males, the mean MIAIA and MIPIA were $29.55^{\circ} \pm 10.21^{\circ}$ and $25.74^{\circ} \pm 5.47^{\circ}$, respectively; in famales, the values were $36.34^{\circ} \pm 11.16^{\circ}$ and $30.45^{\circ} \pm 11.21^{\circ}$, respectively. These results were not significantly different in different sexes $(P>0.05$, Table 2$)$.

As viewed from insertion point $\mathrm{C}$, the mean MIMIA was smaller in males than in females $\left(-5.31^{\circ} \pm 3.69^{\circ}\right.$ and $1.75^{\circ} \pm 8.95^{\circ}$, respectively, and the negative value of the MIMIA indicated that the screw was placed in lateral inclination rather than in medial inclination). The angle was significantly different in different sexes $(P<0.05$, Table 3$)$. These results indicate that the screw at the line tangential to the acetabulum had more of an outward tilt angle in males than that in females. The mean MAMIA was not significantly different in different sexes ( $P>0.05$, Table 3$)$. The mean MIAIA and MIPIA were $56.14^{\circ} \pm 8.92^{\circ}$ and $-5.12^{\circ}$ $\pm 2.89^{\circ}$, respectively, in males; Likewise, the angles were $61.21^{\circ} \pm 10.66^{\circ}$ and $2.33^{\circ} \pm 5.20^{\circ}$ in females, respectively, (the negative value of the MIPIA indicated that the screw was placed in anterior inclination rather than in posterior inclination). The values were not significantly different between males and females $(P>0.05$, Table 3$)$.

Clinical cases

As shown in Fig 5, we can observe the three imaging pictures A-C from a 45-year-old man who was injuried by a car accident. The red arrow represents the displaced quadrilateral plate fracture. Before the operation, we imported his CT-scan images into Mimics software for detailed research. After reduction, two 3.5-mm cortical bone screws were used to fasten the quadrilateral plate (green arrow shown in imaging D-F). Fig 6 shows X-ray and CT-scan from a 51-year-old man who also suffered by serious traffic injuries. We placed two hollow countersunk screws to fix the quadrilateral plate which also got a good reduction. 


\section{Discussion}

Currently, the anterior ilioinguinal approach is commonly used in treating patients with pelvic and acetabular fractures[18,19]. Internal fixation with a screw-plate system is currently the most frequent method of fixing acetabular fractures, and plate placement on the superior border of the arcuate line is commonly used[7, 20-22]. With the ilioinguinal approach, the area of the projection of the acetabulum onto the anterior surface can be exposed through the middle window[1].

Quadrilateral plate is an area like a trapezoid. It is bound by the obturator foramen anteriorly, the greater sciatic foramen posteriorly, the pelvic arcuate line superiorly, and the horizontal line joining the obturator foramen and the ischial spine inferiorly[23,24]. Because of the special location of quadrilateral plate, soft tissue structures are at risk when fixing quadrilateral plate fractures. Bleeding from the corona mortis, direct or indirect injury of obturator vassels and nerve, and urinary bladder direct injury by retractors are common complications[25,26]. Quadrilateral plate fractures are mostly encountered in both columns fractures, accompanied with central dislocations of the hip. In addition, T-type fractures, anterior column and posterior hemi-transverse fractures, posterior column and transverse fractures also involve this inside wall[27,28]. Open reduction and internal fixation with spring plates, H-shaped, T-shaped, L-shaped and reconstruction plates buttressing quadrilateral surface, even with cerclage wiresall are the common methods[29-31]. In some other studies, buttress plates have proved helpful to maintain the quadrilateral surface or medial acetabular wall[21,32]. However, the quadrilateral plate is too thin and located in the dangerous zone, so these technologies are indirect or elastic fixation. In some studies, it is considered that the screws have to run parallel to the anterior border of the greater sciatic notch and parallel to the quadrilateral plate[1,18,33]. However, it has some limitations on the insertion point in clinical practice. What is more, if the quadrilateral plate is too thin, we can not place the screw in parallel and have to take a certain tilt angle. There is no systematic study in which screws are placed in the dangerous zone to fix the quadrilateral plate directly. In other words, it is very difficult to place a double cortical screw in the danger zone to fix the quadrilateral plate[7].

The combination of Mimics software and CT data not only saves manpower, materials and financial resources, but also can be repeated and verified by test results with high reliability in guiding practice[34]. At present, this combination has been widely used in basic and clinical trial studies[35-37]. This digital anatomical measurement provides a reference for screw placement in pelvic and acetabular fractures. In this study, we confirmed the locations of three insertion points according to the location of the arcuate line. We studied the screw placement penetrating the double cortices via four different angles. As shown in Figure 2-4, we could operate the drill-bit in safe angles from Point A, B and C during the surgery.

In this study, we demonstrated that screw placement in the dangerous zone of the anterior surface of the acetabulum could be used as a common method for the treatment of acetabular fracture. Our results were conducted to find the ranges of effective and safe angles. Given the data obtained from our experiment, more screws could be applied to increase stability, without penetrating into the acetabulum. 
As shown in Tables 1 and 3, the MIMIA from insertion point A and $C$ in males was significantly smaller than that in females. Consequently, it can be seen that females required a greater tilt towards the quadrilateral plate surface than males to avoid screw penetration of the joint. The reason for this may be that the thickness of the acetabular medial wall in this region was smaller in females than that in males. There were no significant differences in angles between males and females in terms of point $B$, as shown in Table 2. We speculated that this could be due to the larger femoral head and wider acetabular margin in males, even though the thickness of the medial wall of the acetabulum was smaller in females.

Some related studies have reported screw placement in the dangerous zone of the acetabulum. Our data differ from those of some previous studies. Benedetti[38] selected the vertical line of the anterior surface of the front column as the reference for screw placement. However, this landmark is unreliable for the irregular outline. As the quadrilateral plate is relatively flat, it is very convenient to touch or mark its direction with a Kirschner wire. Therefore, in our study, we considered the quadrilateral plate as a reference to determine the angle of the screw, which could ensure the accuracy of the screw placement. In contrast to the research of $\mathrm{Ji}$ et al[14], we also performed a study of the anterior and posterior angles of screw placement. As shown in Figs 2-4, anterior and posterior inclination screws were long and able to penetrate into bilateral cortices. These screws are more stable than inward tilted screws and can be widely used in clinical practice. Confirmation of the screw insertion sites was decided by the holes on the steel plate in some related digital anatomical studies[34]. In our study, we determine the insertion points through the holes of reconstruction plate. In the actual operation, 1 or 2 screws can also be placed first to secure the reduction of quadrilateral plate fracture, as shown in Fig 5 and 6 . Then, the contoured plate can be inserted to strengthen the fixation.

Mimics software has been widely used in 3D reconstruction for the development of digital orthopedics technology. Preoperative 3D modelling enables more effective diagnosis and simulates the surgical procedure[39-44]. Our study provides surgeons with accurate data for selecting the correct zones of entry and angles before the implantation of screws. The fracture line is often in the danger zone, but we can place the screws into quadrilateral plate and control the angle to ensure double cortices.

There are some limitations to this study. We only studied the fixation of the fracture. However, how to perform fracture reduction was not mentioned. We only researched the common method of plate placement (superior border of the arcuate line). In addition, more patterns of fixation should be considered. If the fracture is comminuted severely, screws cannot be applied after reduction, especially for severe quadrilateral plate fractures. We only studied the pelvises of Chinese people, who have different skeletal shapes than American and European populations. In addition, we did not collect data according to height, weight or body bone density. Moreover, during the actual operation, we had to account for not only the bone but also the soft tissue. These factors may affect the implantation of screws.

\section{Conclusion}


Our results imply that the direct implantation of screws for quadrilateral plate fractures in the dangerous zone of the acetabulum with the use of preoperative measurements and calculations by digital tools are feasible. Mimics software can be used for 3D reconstruction, imitating screw implantation, and reducing unnecessary injury during operation. Double cortical screws could be placed stably and safely through the middle window of ilioinguinal approach.

\section{Abbreviations}

CT: computed tomography; 3D: three-dimensional reconstruction; MIMIA: minimum medial inclination angle; MAMIA: maximum medial inclination angle; MIAIA: minimum anterior inclination angle; MIPIA: minimum posterior inclination angle; Mimics: Materialise's Interactive Medical Image Control System.

\section{Declarations}

\section{Ethics approval and consent to participate}

All patients have been fully informed the contents of this study, consented to participate in this study and signed informed consents form. This study was approved by the ethics committee of Liaocheng People's Hospital.

\section{Consent for publication}

The patient featured in Fig. 5 and 6 has been informed of this study and consented the publication.

\section{Availability of data and materials}

All the data used in this article was collected from the patients and cannot be shared for privacy.

\section{Competing interests}

We have no conflict of interest concerning the materials or methods used in this study or the findings specified in this article. The authors declare that they have no competing interests.

\section{Funding}

No funding was received in support of this investigation.

\section{Authors' contributions}


All authors were involved in drafting the article or revising it critically for important intellectual content. BZ had full access to all the data in the study and took responsibility for the integrity of the data and the accuracy of data analysis. Study conception and design: BZ, WDM. Acquisition of data: BZ. Analysis and interpretation of data: BZ, WDM. All authors read and approved the final manuscript. BZ, WDM performed the operations. All authors above have read this manuscript and approved for this final version.

\section{Acknowledgements}

We would like to acknowledge the reviewers for their helpful comments on this paper. Thanks to Dr. Zhongbao Xu for helping perform the operations.

\section{References}

1. Fensky F, Lehmann W, Ruecker A, et al. Ilioinguinal Approach[J]. Journal of Orthopaedic Trauma, 2018, 32:S12-S13. 2. Kacra B K, Arazi M, Cicekcibasi A E, et al. Modified medial Stoppa approach for acetabular fractures: an anatomic study.[J]. Journal of Trauma \& Acute Care Surgery, 2011, 71(5):1340-1344. 3. Ebraheim N A, Waldrop J, Yeasting R A, et al. Danger zone of the acetabulum.[J]. Journal of Orthopaedic Trauma, 1992, 6(2):146-51. 4. Xu R, Ebraheim N A , Farooq A, et al. Placement of screws in the uncemented acetabulum: anatomic analysis of the danger zone.[J]. Orthopedics, 1997, 20(8):699. 5. Wang X Q, Zhang W, Sun S, et al. Anatomic study of internal fixation of acetabular anterior column plate technique.[J]. Zhonghua wai ke za zhi, 2006, 44(24):1700. 6. Guy P, Ej A O M , Helmy N. The 'safe zone' for extra-articular screw placement during intra-pelvic acetabular surgery.[J]. Journal of Orthopaedic Trauma, 2010, 24(5):279-83. 7. White G , Kanakaris N K, Faour O , et al. Quadrilateral plate fractures of the acetabulum: An update[J]. Injury, 2013, 44(2):159-167. 8. Anglen JO, DiPasquale T. The reliability of detecting screw penetration of the acetabulum by intraoperative auscultation. J Orthop Trauma, 1994 Oct; 8(5): 404-8. 9. Ebraheim NA, Savolaine ER, Hoeflinger MJ, Jackson WT. Radiological diagnosis of screw penetration of the hip joint in acetabular fracture reconstruction. J Orthop Trauma, 1989; 3(3): 196201. 10. Carmack DB, Moed BR, McCarroll, K, Freccero D. Accuracy of detecting screw penetration of the acetabulum with intraoperative fluoroscopy and computed tomography. J Bone Joint Surg Am, 2001 Sep; 83-A(9):1370-5. 11. Caviglia H, Mejail A, Landro ME, et al. Percutaneous fixation of acetabular fractures. EFORT Open Rev. 2018 May; 3(5): 326-334. 12. Zhang S, Su W, Luo Q, et al. Measurement of the "Safe Zone" and the "Dangerous Zone" for the Screw Placement on the quadrilateral surface in the treatment of pelvic and acetabular fractures with stoppa approach by computational 3D Technology. Biomed Res Int. 2014; 2014: 386950. 13. Chen H, Tang P, Yao Y, et al. Anatomical study of anterior column screw tunnels through virtual three-dimensional models of the pelvis. Eur J Orthop Surg Traumatol. 2015 Jan; 25(1): 105-10. 14. Ji X, Bi C, Wang F, et al. Digital anatomical measurements of safe screw placement at superior border of the arcuate line for acetabular fractures. BMC Musculoskelet Disord. 2015 Mar 15; 16:55. 15. Jiantao L, Hao Z, Peng Y, et al. A New Measurement Technique of the Characteristics of Nutrient Artery Canals in Tibias Using Materialise's Interactive Medical Image Control System Software[J]. BioMed Research International, 2015, 2015:1-7. 16. Tang M, Yin Z, Morris S F. A Pilot Study on ThreeDimensional Visualization of Perforator Flaps by Using Angiography in Cadavers[J].Plastic and 
Reconstructive Surgery,2008, 122(2):429-437. 17. Shuxian Z, Wanhua Z, Bingheng L. 3D reconstruction of the structure of a residual limb for customising the design of a prosthetic socket[J]. MEDICAL

ENGINEERING \& PHYSICS, 2005, 27(1):67-74. 18. Matta JM. Operative treatment of acetabular fractures through the ilioinguinal approach: a 10-year perspective. Clin Orthop Relat Res.1994 Aug; (305): 10-19. 19. Stöckle U, Hoffmann R, Südkamp NP, Reindl R, Haas NP. Treatment of complex acetabular fractures through a modifed extended iliofemoral approach. J Orthop Trauma 2002 Apr; 16 (4): 220-30. 20. Uchida $\mathrm{K}$, Kokubo $\mathrm{Y}, \mathrm{Takafumi}$ Yayama, et al. Fracture of the acetabulum: a retrospective review of ninety-one patients treated at a single institution[J]. European Journal of Orthopaedic Surgery \& Traumatology, 2013, 23(2):155-163. 21. Karim M A , Abdelazeem A H , Youness M , et al. Fixation of quadrilateral plate fractures of the acetabulum using the buttress screw: A novel technique[J]. Injury, 2017 Aug; 48(8):18131818. 22. Hirvensalo E, Lindahl J, Kiljunen V. Modified and new approaches for pelvic and acetabular surgery. Injury. 2007; 38(4): 431-41. 23. Elnahal W A , Karim M A , Khaled S A , et al. Quadrilateral Plate Fractures of the Acetabulum: Proposition for a Novel Classification System[J]. Injury, 2017, 49(2). 24. Laflamme G Y , Delisle J , Leduc $S$, et al. Isolated quadrilateral plate fracture: an unusual acetabular fracture[J]. Canadian Journal of Surgery, 2009, 52(5):217-9. 25. Khoury A, Weill Y, Mosheiff R. The Stoppa approach for acetabular fracture[J]. Oper Orthop Traumatol, 2012, 24(4-5):439-448. 26. Schwabe $P$, Wichlas $F$, Druschel $C$, et al. Complications after osteosynthetic treatment of acetabular fractures[J]. Orthopäde, 2014, 43(1):24-34. 27. Qureshi A A , Archdeacon M T , Jenkins M A , et al. Infrapectineal Plating for Acetabular Fractures: A Technical Adjunct to Internal Fixation[J]. Journal of Orthopaedic Trauma, 2004, 18(3):175-178. 28. Laflamme G Y , Hebert-Davies J, Rouleau D, et al. Internal fixation of osteopenic acetabular fractures involving the quadrilateral plate[J]. Injury-international Journal of the Care of the Injured, 2011, 42(10):1130-1134. 29. Matta J M , Mehne D K, Roffi R. Fractures of the acetabulum. Early results of a prospective study.[J]. Clin Orthop Relat Res, 1986, 205(205):241-250. 30. Giannoudis P V , Grotz M R W , Papakostidis C, et al. Operative treatment of displaced fractures of the acetabulum[J]. China Journal of Orthopaedics \& Traumatology, 2005, 87(1):2-9. 31. Makwana K, Vijayvargiya $\mathrm{M}$, Agarwal $\mathrm{N}$, et al. A rare case of bilateral central subluxation of the hip joint with associated bilateral quadrilateral plate fracture in an elderly male due to seizure activity[J]. Rev Bra Orto, 2018; 53(4):489-492. 32. Peter, Robin E. Open reduction and internal fixation of osteoporotic acetabular fractures through the ilio-inguinal approach: use of buttress plates to control medial displacement of the quadrilateral surface[J]. Injury, 2015, 46:S2-S7. 33. Kaifang C, Yanhui J , Zhenfei H, et al. A single modified ilioinguinal approach for the treatment of acetabular fractures involving both columns[J]. Journal of Orthopaedic Trauma, 2018:1. 34. Li W, Zhao F, Sun Z, et al. Digital Anatomy to Improve Screw Insertion Techniques for Plate-Screw Fixation of the Pubic Body. Biomed Res Int. 2018; 2018: 4690879. 35. Popat $H$, Richmond S, Benedikt $L$, et al. Quantitative analysis of facial movement-a review of threedimension imaging techniques. Computerized Medical Imaging $\otimes$ Graphics the Official Journal of the Computerized Medical Imaging Society, 2009, 33 (5): 377 - 383. 36. Guo H, Wang Y, Dai J, et al. Application of 3D printing in the surgical planning of hypertrophic obstructive cardiomyopathy and physician-patient communication: a preliminaiy study. J Thorac Dis, 2018,10 (2): 867-873. 37. Chang S, Yang Y, Liu Y, et al. How Does the Remodeling Capacity of Children Affect the Morphologic Changes of Fractured Mandibular Condylar Processes After Conservative Treatment? J Oral Maxillofac Surg. 2018 
Jun; 76(6): 1279.e1-1279.e7. 38. Benedetti JA, Ebraheim NA, Xu R, et al. Anatomic considerations of plate-screw fixation of the anterior column of the acetabulum. J Orthop Trauma, 1996; (4): 264-72. 39. Chana Rodríguez F, Pérez Mananes R, Narbona Cárceles F.J, et al. 3D printing utility for surgical treatment of acetabular fractures[J]. Rev Esp Cir Ortop Traumatol, 2018, 62(4):231-239. 40. Yu A W , Duncan J M , Daurka J S, et al. A Feasibility Study into the Use of Three-Dimensional Printer Modelling in Acetabular Fracture Surgery[J]. Advances in Orthopedics, 2015, 2015:1-4. 41. Duncan J M , Samuel N, Kashif A, et al. The Use of a 3D Printer in Pre-operative Planning for a Patient Requiring Acetabular Reconstructive Surgery:[J]. Journal of Orthopaedic Case Reports, 2015, 5(1):23-25. 42. Mitchell S. Tactile surgical navigation system for complex acetabular fracture surgery.[J]. Orthopedics, 2014, 37(4):237-42. 43. Chen $X$, Chen X, Zhang G, et al. Accurate fixation of plates and screws for the treatment of acetabular fractures using 3D-printed guiding templates: An experimental study[J]. Injury, 2017 Jun; 48(6): 11471154. 44. Lalit $M$, Abhishek $M$, Gaurang $A$, et al. 3D printing in designing of anatomical posterior column plate[J]. Journal of Clinical Orthopaedics and Trauma, 2018;9(3):236-240.

\section{Tables}

Table 1: Measured angles from insertion point A.

\begin{tabular}{lcccc}
\hline Group & $\operatorname{MIMIA}\left({ }^{\circ}\right)$ & $\operatorname{MAMIA}\left({ }^{\circ}\right)$ & $\operatorname{MIAIA}\left({ }^{\circ}\right)$ & $\operatorname{MIPIA}\left({ }^{\circ}\right)$ \\
& & & & \\
\hline Male$(\mathrm{n}=50)$ & $4.96 \pm 1.11$ & $33.75 \pm 8.27$ & $-1.49 \pm 6.29$ & $45.75 \pm 6.13$ \\
Female(n=50) & $8.66 \pm 3.40$ & $25.60 \pm 4.77$ & $1.81 \pm 7.58$ & $48.45 \pm 14.69$ \\
t value* & -3.260 & 2.701 & -1.062 & -0.535 \\
& & & & \\
P value* & 0.014 & 0.077 & 0.344 & 0.602 \\
& & & & \\
\hline
\end{tabular}

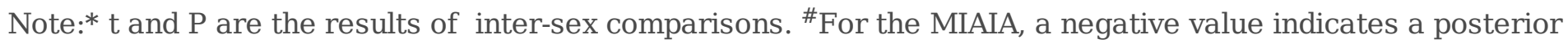
inclination.

Table 2: Measured angles from insertion point B. 


\begin{tabular}{lcccc}
\hline Group & $\operatorname{MIMIA}\left({ }^{\circ}\right)$ & $\operatorname{MAMIA}\left({ }^{\circ}\right)$ & $\operatorname{MIAIA}\left({ }^{\circ}\right)$ & $\operatorname{MIPIA}\left({ }^{\circ}\right)$ \\
\hline Male(n=50) & $13.05 \pm 2.67$ & $27.36 \pm 5.19$ & $29.55 \pm 10.21$ & $25.74 \pm 5.47$ \\
Female(n=50) & $12.05 \pm 2.24$ & $24.69 \pm 3.13$ & $36.34 \pm 11.16$ & $30.45 \pm 11.21$ \\
t value* & 0.904 & 1.393 & -1.418 & -1.193 \\
& & & & 0.058 \\
P value* $^{0.537}$ & 0.054 & 0.576 & \\
\hline
\end{tabular}

Note:* $\mathrm{t}$ and $\mathrm{P}$ are the results of inter-sex comparisons.

Table 3: Measured angles from insertion point C.

\begin{tabular}{lcccc}
\hline Group & $\operatorname{MIMIA}^{\#}\left({ }^{\circ}\right)$ & $\operatorname{MAMIA}\left({ }^{\circ}\right)$ & $\operatorname{MIAIA}\left({ }^{\circ}\right)$ & $\operatorname{MIPIA}^{\#}\left(^{\circ}\right)$ \\
\hline Male(n=50) & $-5.31 \pm 3.69$ & $24.73 \pm 1.95$ & $56.14 \pm 8.92$ & $-5.12 \pm 2.89$ \\
Female(n=50) & $1.75 \pm 8.95$ & $23.90 \pm 2.46$ & $61.21 \pm 10.66$ & $2.33 \pm 5.20$ \\
t value* & -2.304 & 0.833 & -1.153 & -3.952 \\
& & & & \\
P value* & 0.008 & 0.849 & 0.856 & 0.101 \\
& & & & \\
\hline
\end{tabular}

Note:* $\mathrm{t}$ and $\mathrm{P}$ are the results of inter-sex comparisons. ${ }^{\#}$ For the MIMIA, a negative value indicates a lateral inclination. For the MIPIA, a negative value indicates an anterior inclination.

\section{Figures}




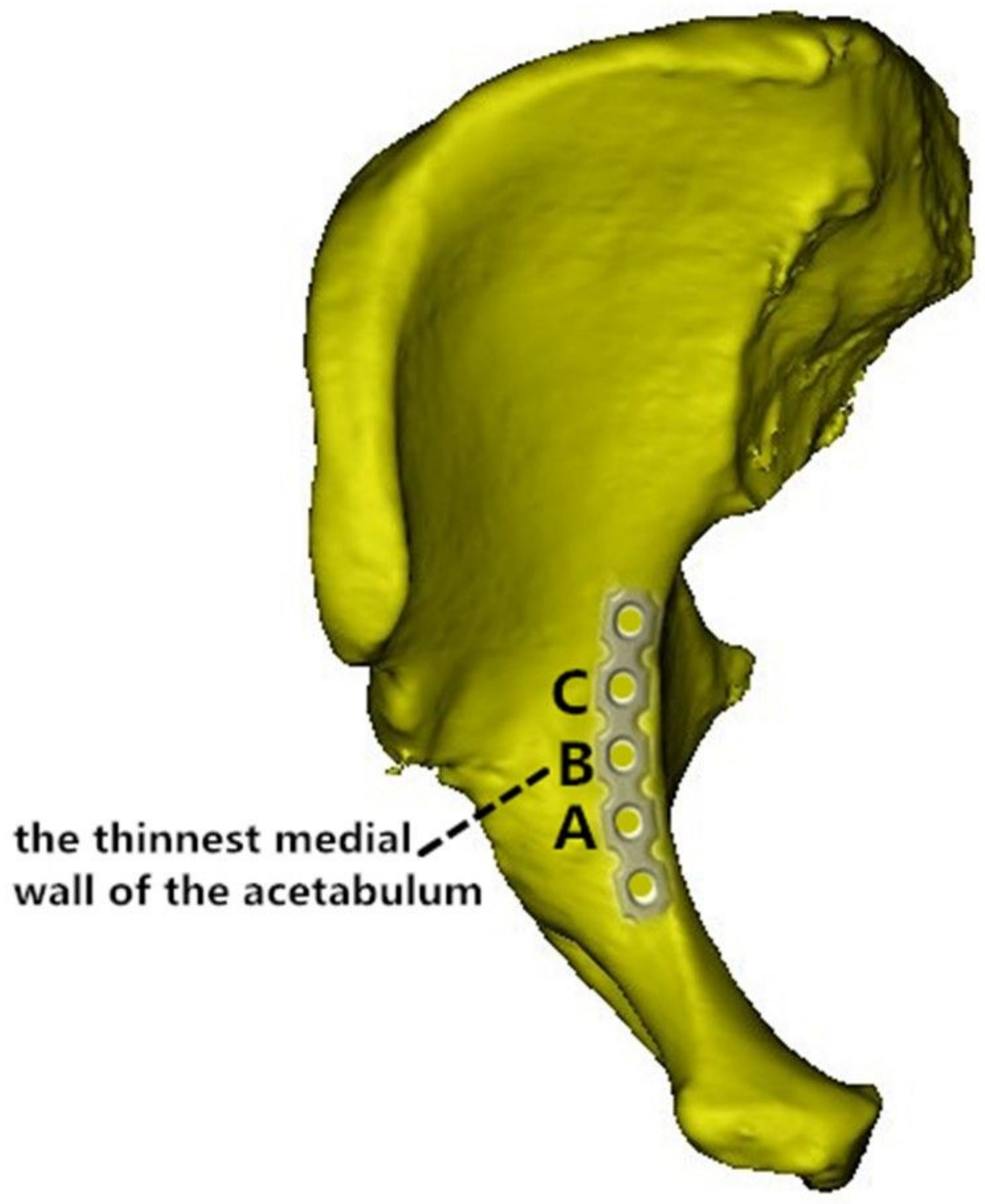

\section{Figure 1}

Plate was placed on the superior border of the arcuate line in the 3D reconstruction. The distance between the plate hole and the arcuate line was $5 \mathrm{~mm}$. Insertion point B (plate hole B) corresponded to the-thinnest medial wall of the acetabulum. Insertion point $A$ and $C$ were the two holes close to plate hole $B$, respectively. 

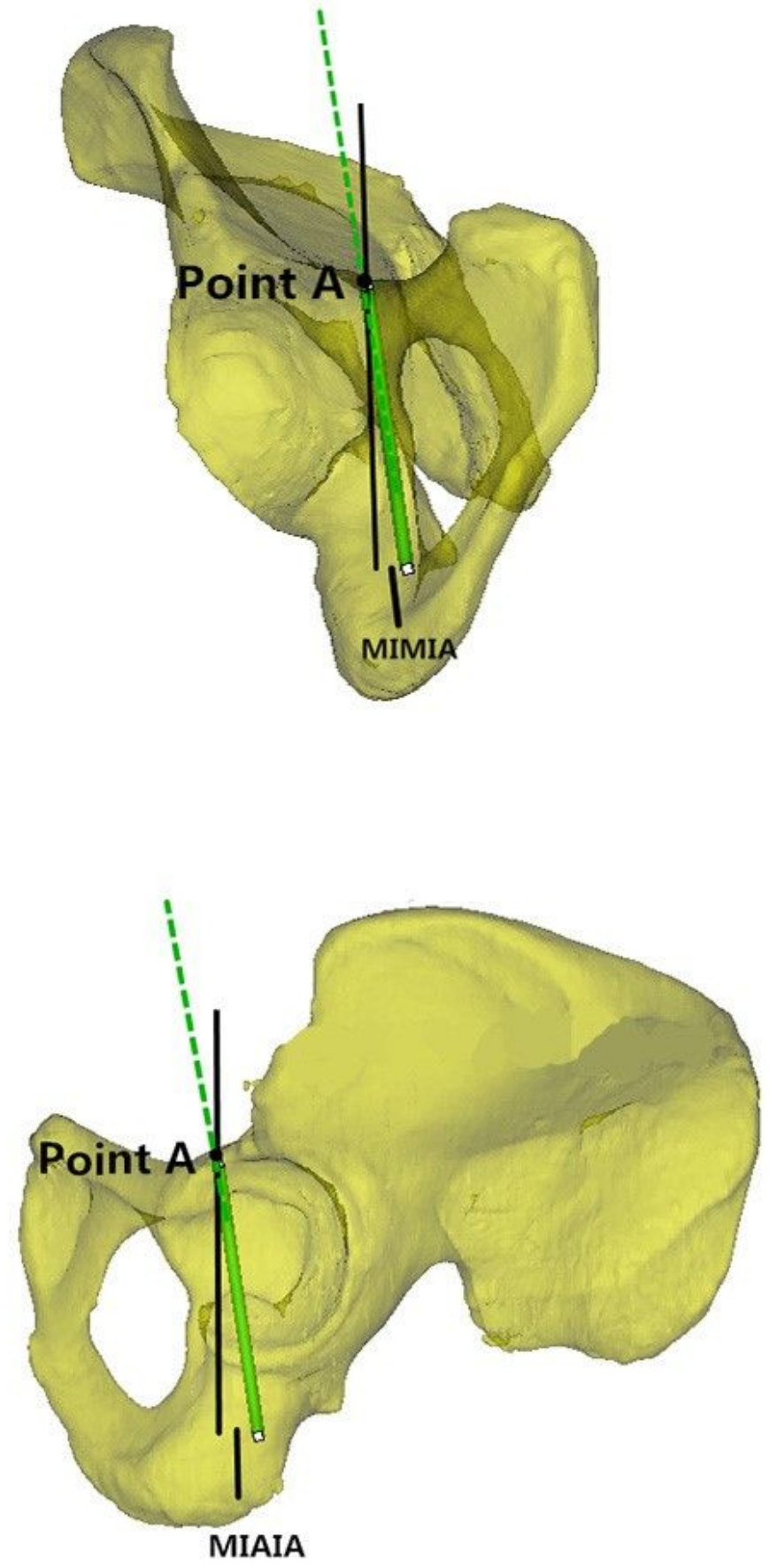
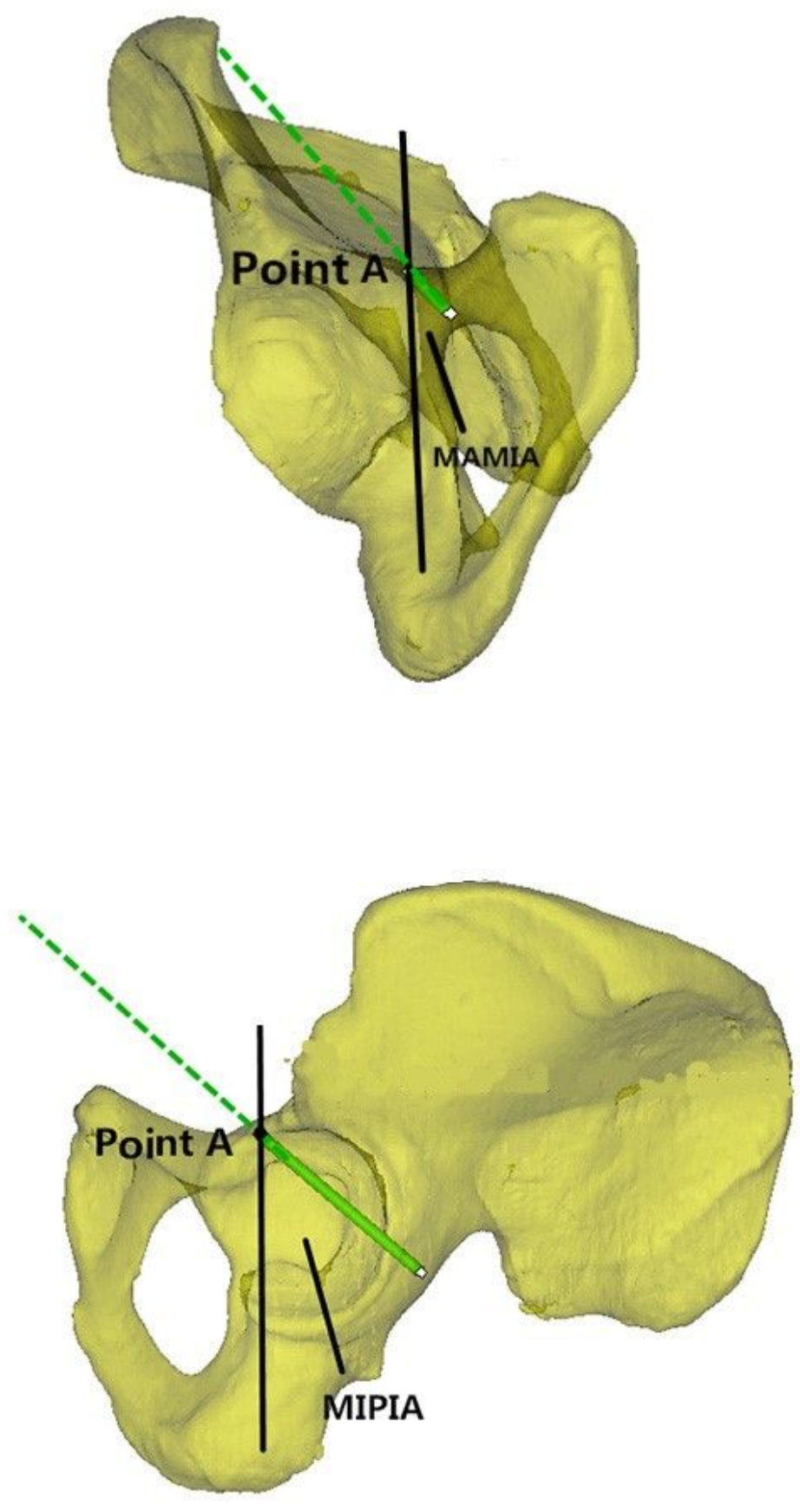

\section{Figure 2}

The illustration presenting the angles for safely introducing the drill-bit from Point A(simulating a clinical scenario): the angle between the green dotted line and the black solid line represents the angle of drill. With quadrilateral plate as a sign, we can see the range of four different angles in male and female. 

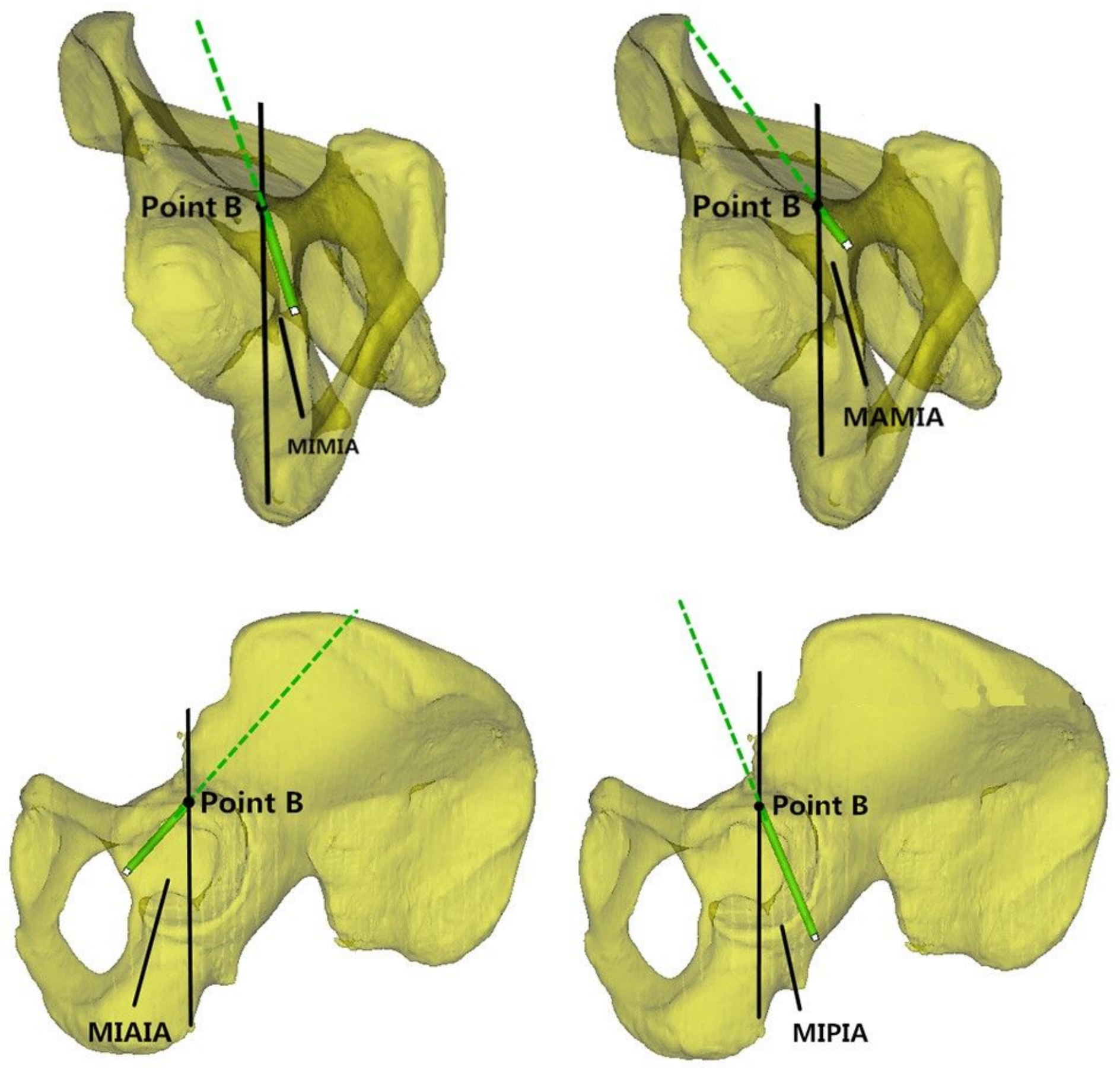

\section{Figure 3}

The illustration presenting the angles for safely introducing the drill-bit from Point B(simulating a clinical scenario): the angle between the green dotted line and the black solid line represents the angle of drill. With quadrilateral plate as a sign, we can see the range of four different angles in male and female. 

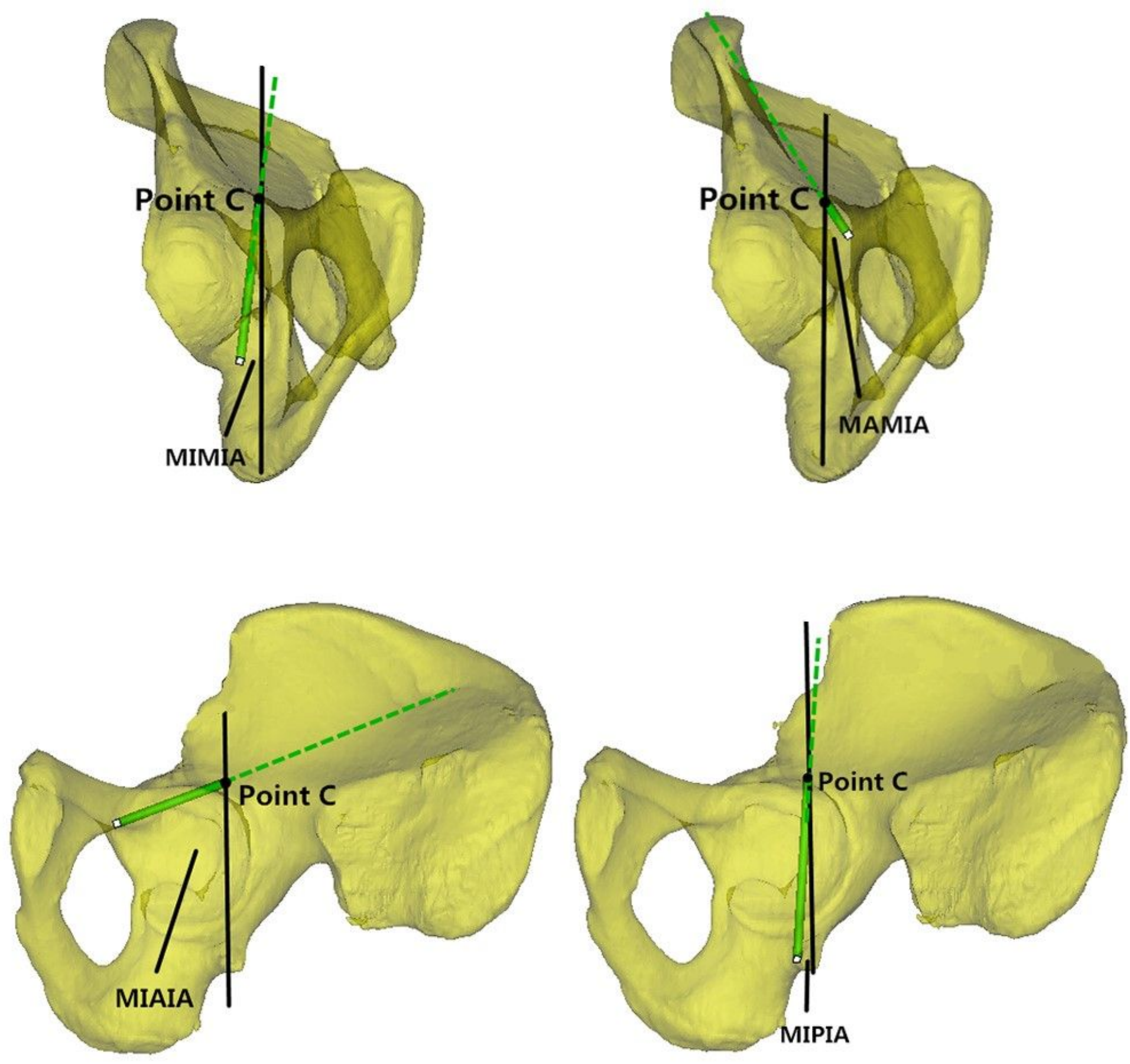

Figure 4

The illustration presenting the angles for safely introducing the drill-bit from Point $\mathrm{C}$ (simulating a clinical scenario): the angle between the green dotted line and the black solid line represents the angle of drill. With quadrilateral plate as a sign, we can see the range of four different angles in male and female. 


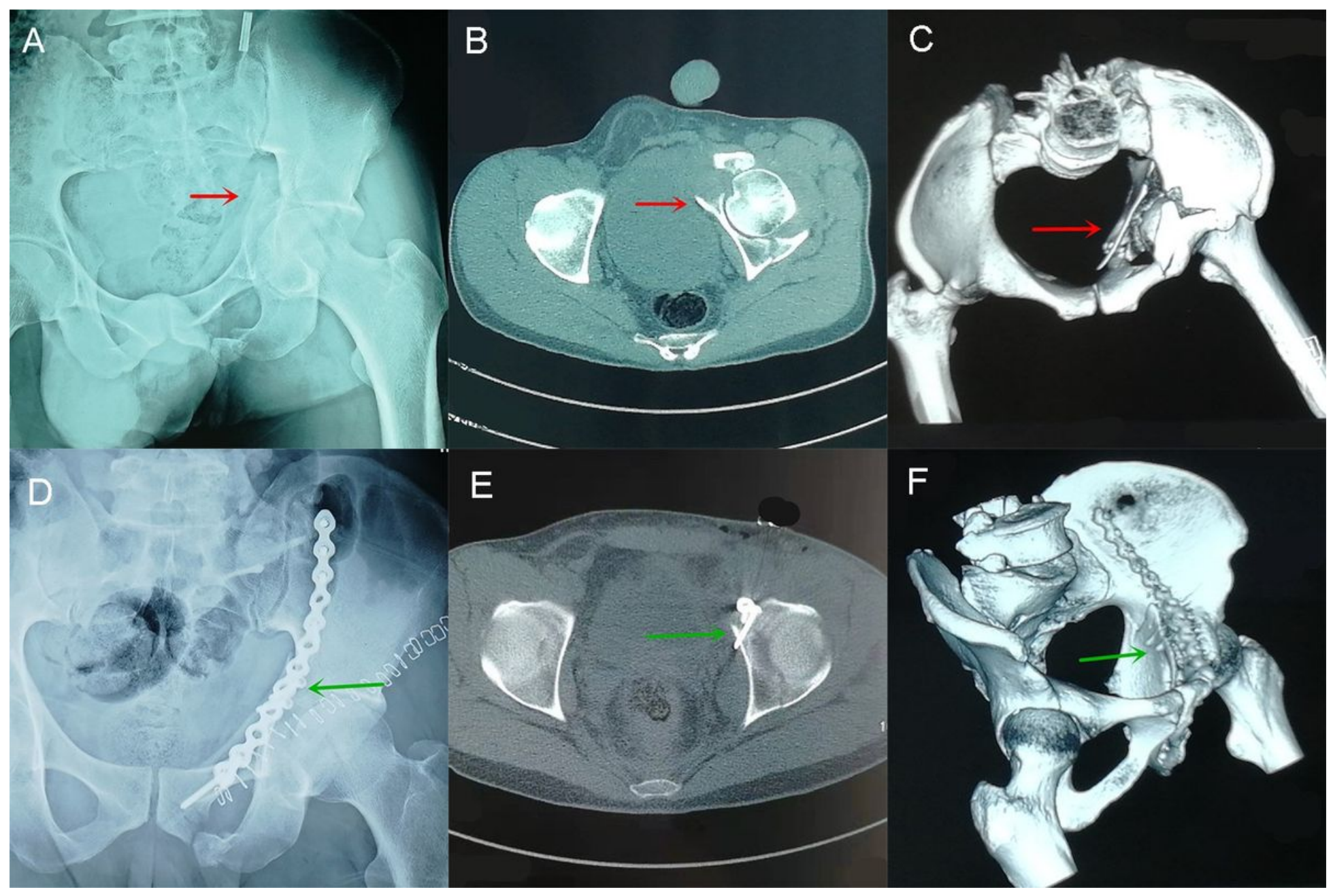

Figure 5

A 45-year-old man was injuried by a car accident. A-C: preoperative X-Ray, CT cross section and 3D reconstruction. The red arrow represents the displaced quadrilateral plate fracture. D-F: postoperative XRay, CT cross section and 3D reconstruction. Green arrow shows two 3.5-mm cortical bone screws used to fix the quadrilateral plate. 


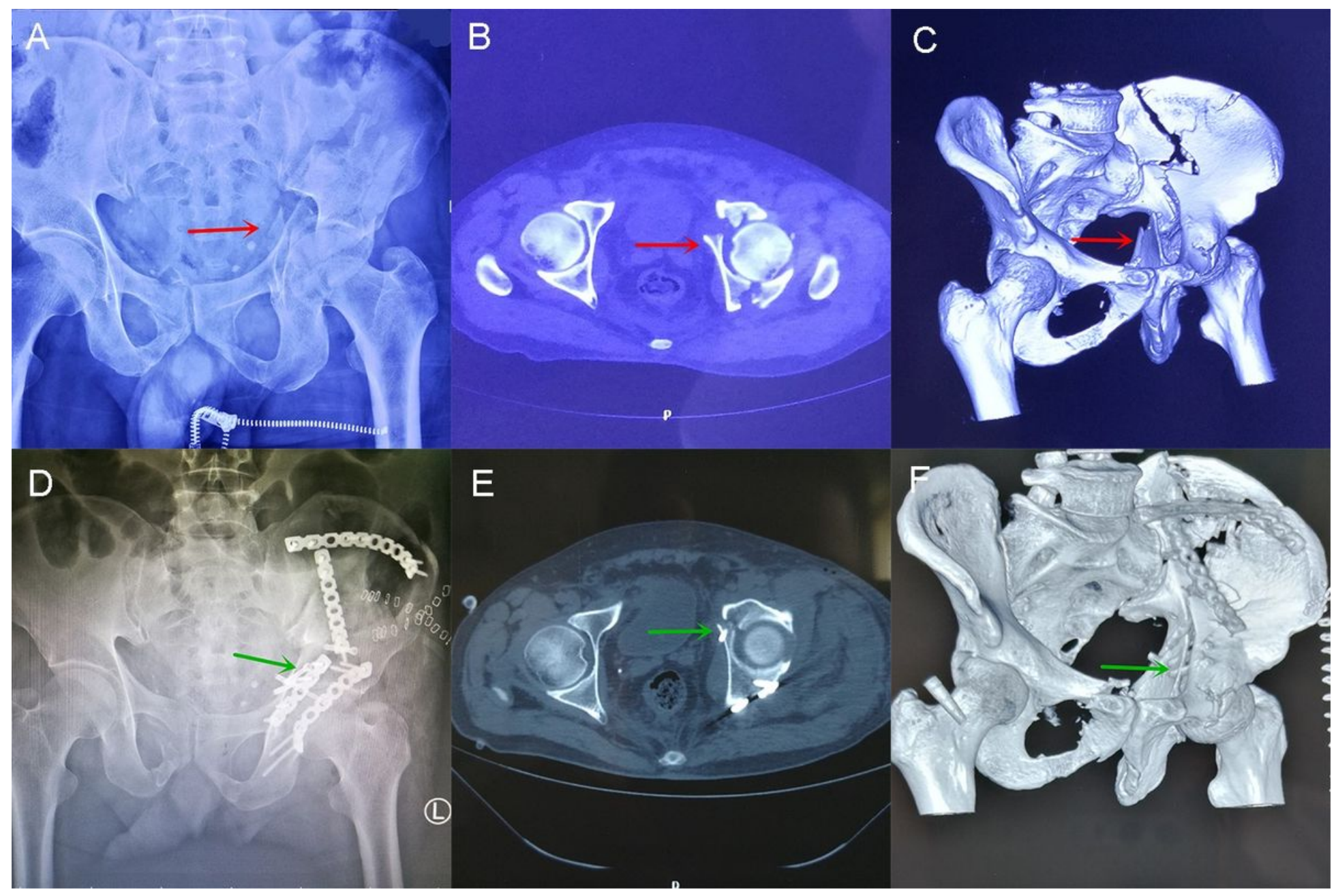

\section{Figure 6}

A 51-year-old man was suffered by serious traffic injuries. A-C: preoperative X-Ray, CT cross section and $3 \mathrm{D}$ reconstruction. The red arrow represents the displaced quadrilateral plate fracture. D-F: postoperative X-Ray, CT cross section and 3D reconstruction. Green arrow shows two hollow countersunk screws used to fix the quadrilateral plate. 